\title{
Practical Exploration on Constructing Efficient VFP Program Design Course classroom in Higher Vocational College
}

\author{
JIANG Yong-Chun \\ Qingdao Huanghai University \\ Qingdao, Shandong, China 266427
}

\author{
XU Yuan-Yuan \\ Qingdao Huanghai University \\ Qingdao, Shandong, China 266427
}

\begin{abstract}
Efficient classroom teaching in primary and secondary schools has achieved initial success, but whether the curriculum for Higher Vocational and Technical College can also use the efficient classroom, there are still a lot of controversy. Aiming at the teaching of VFP programming course, this paper uses "efficient classroom" teaching method, gives students class initiative based on task-driven way, and enables students to master curriculum theories and methods through the classroom case operation. Through teaching mode of constructing efficient classroom for the accounting computerization majors in our college students, good teaching effect is achieved in the VFP programming course.

Efficient classroom is currently promoted in the reform of curriculum in primary and secondary schools, and generally recognized by students. Can efficient classroom be built in the higher vocational classes? Through teaching mode change of VFP program design course for class of 2014 accounting electrical calculating majors in the school in a semester, to build efficient classroom teaching mode, to use task driven teaching method in the classroom, to enable students to shift the passive reception to active learning, to embody students as the subject of study, and fully liberate teachers, to improve the classroom efficiency in $\mathbf{4 5}$ minutes, to stimulate students interest in learning, and also enhance the students hands-on practice operation ability.[1]
\end{abstract}

Keywords-Efficient classroom; VFP program design; The teaching method; Higher vocational college

\section{EFFICIENT CLASSROOM}

\section{A. The Efficient Classroom}

Efficient classroom, is short for efficient type classroom or efficiency class, just as its name implies, refers to the classroom of high education teaching efficiency or effect, specifically refers to, on the basis of effective classroom, the classroom with high impact on education and social benefits, which can complete the teaching task and achieve the teaching goal of high efficiency. Efficient classroom is the highest state of effective classroom, which is based on efficient teaching.[2]

\section{B. Current Situation of VFP Program Design Classroom in Vocational School}

Higher vocational college class differs from that of middle and primary school. It is facing college students of higher education, not the primary and middle school students in compulsory education phase. College students are adults, having their own independent consciousness and control of the emotions of learning. They have the characteristics of the new era: personality, mavericks, egotistic, bold, and good command of modern tools, etc. This requires that we teachers should have a strong classroom control ability, to guide and inspire students' interest in learning. While in the actual teaching process, it is very difficult to fully mobilize students' activity in class performance, it's common to see students use mobile phones to play games, watch movies and TV and chat.

As a required course for higher vocational college, VFP program design course is a two-way comprehensive technology curriculum of the combination of theory and practice. The traditional teaching method in general is a teacher teaches knowledge by multimedia, then sets aside time for student practice, which causes "Cramming education". Students don't listen, and can't finish the practice task. Teachers work really hard while students still learn nothing, and class effect is not obvious.

\section{Practice of EfFicient Classroom}

According to the American education scholar Walter Matt "cooperative learning is the most important and most successful reform of teaching in recent decades. Teachers in the classroom teaching can divide students into groups to carry on the cooperative learning, encourage students in learning to become the" master ", learn to communicate with people and learn cooperatively, be willing to learn, experience the fun of learning. Students are willing to participate in classroom activities. The "passive learning" shift to "active learning", which can promote the formation of efficient classroom. Of course, if teachers can't make students produce learning interests through cooperation, it will be counterproductive. If teachers just divide the students into groups, do not teach students how to communicate, nor supervise the group activity, it is easy to cause confusion, and the classroom can't really play the role of group learning. Based on the teaching practice of VFP program design course of higher vocational accounting computerization majors, the paper will analyze and explore how to construct effective group cooperation and improve classroom efficiency. The specific practice process of building effective classroom takes a lesson of controls on the form as an example. 


\section{A. The Teachers' Preparation}

"A minute on stage, ten years of work off the stage",. To achieve efficient class, the teacher must be well prepared before class, comprehend difficult points in all chapters of the textbook. Because VFP program design is a practice lesson. According to the teaching tasks and goals of the course, combining with the form controls in this chapter and the previous knowledge, teachers should design two cases that accounting majors are familiar with: password authentication and calculator. Write code of objectForm 1 in the case of password authentication and button group commandgroup 1 in calculator case.

load event code of Form1 :

Public I

$\mathrm{I}=0$

Command1 click event code: \&\& sure button design code

$$
\mathrm{I}=\mathrm{I}+1
$$

If thisform. Text1. Value $=$ '123456' \&\& password set

Messagebox (' welcome to system!)\&\& through password authentication, welcome window are presented

Thisform. Release

The else

If $\mathrm{I}<3$

Messagebox (" password is wrong, please try again! ")\&\& wrong password Settings

Thisform. Text1. Value = "'"

Thisform. Text1. Setfocus

The else

Messagebox (' password mistake, not allowed to enter system! ') \&\& input three times wrong password, ban window are presented

Thisform. Release

endif

endif

Command2 click event code: \&\& cancel button on the design code

\section{Thisform. Release}

Button group commandgroup1 click event code

Do the case

Case this. Value $=1$

Thisform. Text3. Value $=$ Thisform. Text1. Value + Thisform. Text2. Value

Case enclosing value $=2$

Thisform. Text3. Value $=$ Thisform. Text1. Value Thisform. Text2. Value

Case enclosing value $=3$

Thisform. Text3. Value $=$ Thisform. Text1. Value * Thisform. Text2. Value

Case enclosing value $=4$

If thisform. Text2. Value\# 0 \&\& judgment the denominator is zero
Thisform. Text3. Value $=$ Thisform. Text1. Value/Thisform text2. Value

The Else

Messagebox (" divisor cannot be zero! ", 48)

Endif

Otherwise

Thisform. Text1. Value $=0$

Thisform. Text2. Value $=0$

Thisform. Text3. Value $=0$

Endcase[3]

\section{B. Classroom Practice}

\section{1) Teachers assign tasks}

Teachers use five minutes in class to review the previous knowledge, to show the implementation process of the two cases, and give tasks. Teams can choose one of the cases and design independently by discussing, and give students 25 minutes to discuss and design, and then use 10 minutes to select some cases and show them, the last5 minutes is for the teacher's comments.

Efficient classroom require teachers talk less, students talk more, practice more and learn more. Teachers just tell students learning methods and contents, students will shift from passive acceptance to active collection. Make students to move, and speak out in front of the classmates. Students change from audience into actors and participants. To rebuild a new classroom order, teachers must overcome student's biggest weakness "inertia" with task pressure.[4]

\section{2) Clarify the responsibility of the team members}

Divide students into teams in the first lesson of the semester. Take the standard class of 45 people as an example, a class can be divided into 7 team, 6-7 people in each team. Team members get a resounding name for themselves, and select the captain, who is responsible to sum knowledge, and complete the function of control, recorder, who is responsible for the summary of classroom theory knowledge induction and notetaking, the operator who is responsible for the writing, debugging, and operation of the program, demonstrator who is responsible for the task of the show, interpreter who is responsible for explanation of each functional module, inspector who is responsible for checking other teams' design and puts forward his own team's advantage, etc.

Each team member has clear responsibilities, and participates actively, which can avoid that some members have nothing to do but to become lazy, and do not participate in learning activities. Usually teachers need to set some rules beforehand, make clear the task of each student, and truthfully record the performance of teams and members in cooperative learning, be clear about the rewards and punishments, encourage students to participate in team learning. Every member in the class plays an irreplaceable role, which requires them not only to clear their own task, and realize their own value, which play the enthusiasm of each team member. The task of each class is divided into corresponding parts according to the number of members. Each member is responsible for his own task. The accomplishment of all tasks need each team 
member complete their respective share of the task, which helps to motivate players' psychology of competition, so that their own job can be done better. Each member is likely to be questioned, which relates to the whole team's honor. If you aren't seriously involved in learning and cannot complete the task, then you cannot answer the question correctly, and affect the whole team's performance. A player not participating in activities will affect the quality of the team's activities. Under the pressure, each member will seriously take part in learning activities.

3) Display, mutual-evaluation of students' designs, summary of theoretical knowledge

The display and mutual-evaluation of students' designs is the highlight of the construction of efficient classroom. The advantage of practice class is multimedia interactive operation. Students can realize the computer presentation by the software operation, while the other students also can see the demonstration process at the same time. The displays of the design work make the students form more intuitive impression, which is more conducive to generate interest in learning this course. Students can also consolidate theory knowledge involved in the works virtually, so that students use the knowledge mastered to achieve the design work.

Through the display of students' design, the teachers and students can both find problems in them. According to these questions, the teachers sum up, analyze through comments, and provide guidance; Students sometimes unconsciously find the existing problem by themselves in presentation and modify the shortage. Teachers, of course, also need to avoid the classroom developing freely, or "show specialist" phenomenon. If teachers assign jobs in the presentation, and expand the participation, it is easy to make the show become "general exhibition", and lost its highlight, and difficult to achieve high efficiency. This requires the teachers in this part have a good ability to control class, and mediate classroom atmosphere on time.[5]

\section{4) Teachers' reviews and summary}

After every team complete the design and exhibition, summary of theory knowledge, teachers should earnestly summarize the advantages and disadvantages of each team and review, and do a systematic explanation of the theory knowledge. Each team vote for the most excellent design work, share the work with other teams for analysis. Let students themselves summarize the shortcomings in the course of design work. The team members discuss and put forward the improvement scheme, and write advantages and disadvantages and improvements on the notebook, then make a comparison with previous works, to strengthen involved theory of knowledge.

\section{Practice Effect of the Efficient Classroom}

A semester's practice proved: building efficient classroom teaching mode in higher vocational college in VFP program design course can fully mobilize students' enthusiasm and initiative of learning; effectively cultivate students' innovation ability and the ability of putting professional theory into practice. At the same time, tasks-driven way can inspire students' innovative thinking, cultivate students' ability of independent analysis and solve problems, better train students' team cooperation ability.

Teachers can respectively observe the design of each team, and master the completion of each team and each member's participation. So that we can stop in time a few students' behavior of playing mobile phone, improve the teachers' ability to control the classroom effectively.

\section{SUMMARY}

The students' ability is not improved by the teachers' teaching in class, nor by listening of reciting, back, but by students' apprehending in the various practice of design, participation, discussion and summary. In the whole teaching process, teachers should not "give them fish", but "teach them to fish"; not teach them truth, but teach students to find the truth. To build efficient classroom in higher vocational college, the teacher should be truly based on the development of the students, give the classroom back to students, take the student as the main body, take teaching materials as the resource and guide, as a pilot or director, leads the students to find direction or move into the role, leave the opportunity for students, let them experience by themselves; Set some questions to the student, let students themselves find the right answer.

\section{REFERENCES}

[1] wangchao, Yang Yuanyuan. Higher vocational college English efficient classroom building strategies [J]. Journal of finance and tax, henan college, 2013, 5. (In Chinese)

[2] PengJiangong. Analyses the university teaching how to build efficient classroom [J].Journal of higher education BBS, 2014, 7. (In Chinese)

[3] PeiHaiGong. VisualFoxPro case 8.0 programming tutorial [M].China railway publishing house, 20011. (In Chinese)

[4] Yang Yingchao Jiang Yongchun, yu-baowang. "task drive+ professional case" teaching mode in VFP program design course practice [J]. Computer knowledge and technology, 2015, 4. (In Chinese)

[5] zhen-duo wang. The program design course teaching method research [J]. Computer knowledge and technology, 2009. (In Chinese) 